\title{
Prickle 8-A new innovative, ecological food made by undergraduate students of the department food science \& nutrition
}

\begin{abstract}
The product that we create is unique, since the main raw material is the prickly pear. It is a ready-to-eat, functional and eco cool dessert, with low fat and low sugar because the ingredient that we used which is vanilla fir honey. The main ingredients are prickly pear juice and prickly pear leavesâ€ $€^{\mathrm{TM}}$ extract from Crete, Greek vanilla â€"fir honey from Mt. Mainalon, flour from seeds of prickly pear from Messinia , cinnamon and clove from Indonesia. It has high nutritional value as the prickly pear, which is the main raw material is not accessible to all and is not used in our country, gives the body 14 amino acids of which 8 of them are indispensable for the operation of the organization. The prick18 is a product that has been based on technical "back to the future", reviving an old recipe from Symi, thus keeping a balance between tradition and technology. The name of our product is prickl 8 and has been based on raw material, pricly pear and the fact that is a fruit that gives the body 14 amino acids of which 8 are indispensable for the operation of the organization. We want to project a different lifestyle with the creation of this product and so we are interested in well-being which is why this product is aimed at diabetics, vegetarians, and athletes. Finally, the packaging that is chosen is the glass which is recyclable, premium and versatile as it is our product.
\end{abstract}

\author{
Volume 4 Issue 3 - 2017
}

\section{Pavlos Poursanidis}

Department of food Science and Nutrition, University of the Aegean-Food Science \& Nutrition, Greece

Correspondence: Pavlos Poursanidis, Department of food Science and Nutrition, University of the Aegean-Food Science \& Nutrition, Metropolite loakeim 2 Myrina, Lemnos 81 400, Greece, Tel +306949252694,

Email poursanidispavlos@gmail.com

Received: October 26, 2015 | Published: May 02, 2017

\section{Introduction}

The department of Food Science \& Nutrition at the University of the Aegean, despite the short time operating and the extreme conditions in which it operates in the island of Lemnos, has achieved important scientific distinctions. Students of this department with constant supervision and assistance of teachers are cooperating with a number of production units in the country operating in the food and drinks. During this cooperation students participate in a competition, which is called "Ecotrophelia", creating new innovative and ecological food products.

In the completion "Ecotrophelia 2015" the department of Food Science \& Nutrition was represented by a team of undergraduate students, in which I was participated with my team. During this participation our team collaborated with the company "APIVITA S.A" in order to create a new innovative and ecological food product. After a research in the global market, we decided which our main ingredient would be in our product, which was the prickly pear and what product is going to be produced. All in all, was decided to produce a cool dessert with prickly pear, reviving an old recipe from the island of Symi and at the same time making known a fruit that is not known in our country. The main idea of our team was to use only Greek main ingredients so as to be characterized as a " $\mathbf{1 0 0 \%}$ Greek product " and also the whole utilization of Opuntia ficus indica .For this reason its main ingredients were the following ones:
i. prickly pear juice
ii. prickly pear leaves' extract
iii. flour from prickly pear seeds

We also used Greek vanilla-fir honey instead of sugar so as to be a product with low contest of sugar. We used this honey, because it is PDO product. (Meli Elatis Menalou Vanilla). Moreover, it was used cinnamon and clove for organoleptic reasons. Our choice to use flour from prickly pear seeds instead of corn flour was so as our product to be a gluten-free product. ${ }^{1}$ Using prickly pear juice \& prickly pear leaves' extract could decrease glycalemic level and blood lipids, help in weight loss and for anticancer properties anti-inflammatory reasons ${ }^{1}($ Table 1$)$.

Table I The nutritional facts of our product

\begin{tabular}{ll}
\hline Nutritional Facts & Per $100 \mathrm{~g}$ \\
\hline Energy & $79.60 \mathrm{kcal}(333.05 \mathrm{kj})$ \\
Protein & $067 \mathrm{~g}$ \\
Carbohydrates & $19.16 \mathrm{~g}$ \\
Sugars & $5.88 \mathrm{~g}$ \\
Fiber & $13.28 \mathrm{~g}$ \\
Fat & $0.51 \mathrm{~g}$ \\
Saturates & $0.06 \mathrm{~g}$ \\
Salt & $0.02 \mathrm{~g}$ \\
Calcium(Ca) & $75.66 \mathrm{mg}(9.46 \%$ RDA $)$ \\
Magnesium(Mg) & $114.54 \mathrm{mg}(30.54 \%$ RDA $)$ \\
Potassium(K) & $296.74 \mathrm{mg}(14.84 \%$ RDA $)$ \\
Vitamin C & $18.87 \mathrm{mg}(23.59 \%$ RDA $)$ \\
\hline
\end{tabular}


But why did we choose prickly pear as the main ingredient of our product? Well, some reasons of our choice are that we want to make known this fruit that is produced in large quantities, but there is no interest in reclaiming. The sad fact is that at the end of summer huge crops are abandoned and rotting. We also choose this forgotten cactus fruit, because we are sensitized by the fact that water is becoming an increasingly precious resource all over the world. Highlighting that has low demand for water (prickly pear need 6-10times less water than other fruit plants).

The name of our product is prickl8 and has been based on raw material, prickly pear and the fact that is a fruit that gives the body 14 amino acids of which $\mathbf{8}$ are indispensable for the operation of the human body. We want to project a different lifestyle with the creation of this product and so we are interested in well-being which is why this product is aimed at diabetics, vegetarians, and athletes (Figure 1).

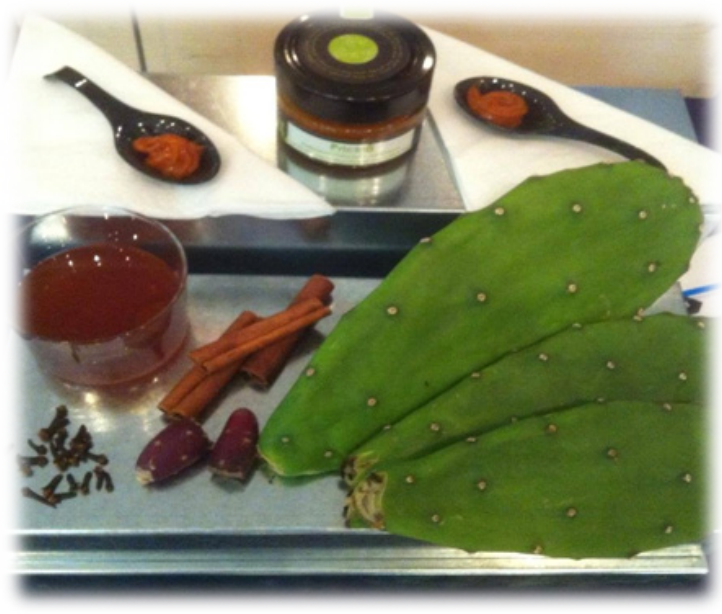

Figure I Our product-Prick|8- as it was presented during the competition Ecotrophelia 'I5'.

\section{Conclusion}

Finally, the packaging that is chosen is the glass which is recyclable, premium and versatile as it is our product.In response to the fact that bees disappearing from chemicals, Prickl 8 includes a seed paper of flower that keeps bees free of pesticides. Maybe it seems like a really small countermeasure to a huge problem, but it is the driver of largescale change. Because when bees have access to good nutrition, we have access to good nutrition through their pollination services. The seed stick, is made from $100 \%$ post-industrial recycled paper and is infused with a resistant mix of vegetable and/or wild flower seeds on its end. By planting it in the package that we chose-glass-after the consumption of our dessert, a plant grows in a few days, by regular watering that is provided. It is in the team's further plans to determine the specific $\mathrm{CF}$ of the product.

\section{Acknowledgments}

All in all, we want to express our thanks to our professor Dr. Skalkos Dimitrios that help us during this effort. We want to mention that this product made by undergraduate students of the department of Food Science \& Nutrition at the University of the Aegean and the state should support these efforts (Figure 2).

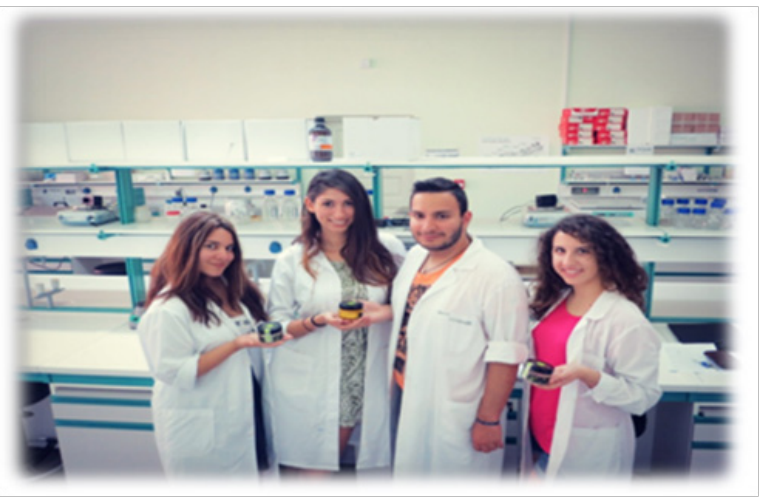

Figure 2 Me and my team during the analysis of our product.

\section{Conflict of interest}

The author declares no conflict of interest.

\section{References}

1. These beneficial properties are according to scientific literature studies and health and nutrition claims. 